Vol. 3, No. 2 | July - December 2020

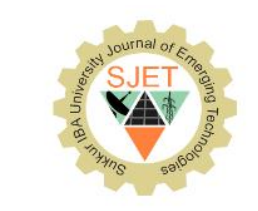

\title{
Modeling and Simulation of Under -Frequency Relay for Generator Protection
}

Ahsan Ali Memon ${ }^{1}$,Mohsin Ali Koondhar ${ }^{1}$, Imdad Ali Memon ${ }^{1}$, Munawar Ayaz Memon ${ }^{1}$, Masood Ali Koondhar ${ }^{1}$, S. Abid Ali Shah Bukhari ${ }^{1}$, Irfan Ali Channa ${ }^{2}$

\begin{abstract}
:
Power systems are undergoing structural changes induced by the combination of the operation of microgrids and distributed generation units. This transfiguration has impersonated new challenges in well-established power system practices, coordination of protection systems and especially on the design. Same time, technological improvements in protective equipment have set up the basis for the development of digital frequency relays (DFL) which enable an alternate approach to standard protection schemes. It is necessary for the power system to operates, regulates and manages ancillary services more efficiently to maintain the reliability of the system. The power system is continually laying unexpected contingencies which cause inequality between load demand and generated power. Such uncertainties cause the disturbance in the power system frequency. The only way to maintain power system frequency by balancing load and generation. In this paper, we have designed the under-frequency relay (UFL) model in Matlab simulink. We have noticed that when the load on the system is increased, the designed model shed the extra load and are modeled through under frequency relay by comparing the frequency responses of the power system.
\end{abstract}

Keywords: synchronous machine; under-frequency relay; relay setting; critical load

\section{Introduction}

Huge generation losses, disturbances and frequencies cause drop rapidly when the generation does not match to the load demand. Reduction of large frequency, overload transmission line, and system collapse can degrade the performance of the load. Stability is one of the most important issues of the power system. The basic problems of voltage, angle and frequency instability occur when there is a huge mismatch between load, and generation or $\mathrm{N}$ 1 probability [1]. Under normal operation of power system, the overall generation of power system must meet to load demand, and loss. The rise in tripping of generation units, transmission lines and load demands can affect voltage, frequency, and may cause in disturbance and dangerous cascading effects $[2,3]$.

Deviations of large frequency can destroy the system and load performance. Turbine governor can take low-level imbalances and have possibilities of damage. However, highlevel imbalances can affect power system and reduce the speed of turbine governor to

${ }^{1}$ Quaid-e-Awam University of Engineering Science \& Technology, Nawabshah, Pakistan

${ }^{2}$ Department of Automation, Beijing University Chemical Technology, Beijing China Corresponding Author: Ahsanmemon444@gmail.com 
respond falling of frequency down below the satisfactory limit [4]. De-energizing the load is very costly and dangerous as well. Load shedding is a very useful scheme in an emergency to control and ensure system stability. Protection scheme is used to return back the system to the normal position and stabilize the frequency of the system. Therefore, extra load to be shaded through the designed scheme in an emergency to avoid the system from collapse and restore the system frequency under the limit by maintaining the balance of load and generation [5, 6].

Load shedding protects the system by declining excessive voltage or frequency to balance the power system and system demand load. Generally, the load shedding scheme involves shedding of predetermined load amount when the frequency drops below some thresholds and is named as under frequency load shedding (UFLS). The purpose of the UFLS system is to restrict very less load, and run the system smooth, quick, and safe from any abnormal condition to a normal state $[1,2]$. The reduction in frequency may cause huge damage to turbines, generators, plants, and can cause their failure at low frequencies. The reason is that their auxiliaries cannot sustain it, and is unable to maintain the normal position when the frequency changes about 10 to $15 \%$ below the normal frequency. Elements which are more sensitive to frequency drops are a synchronous generator, steam turbines and auxiliary services [7 - 9].

A synchronous generator is an important and expensive device of the power systems, and is difficult to be repaired in a short time. It must be protected from abnormal conditions, and faults like overload, unbalancing of loads, excitation losses, stator winding faults, loss of synchronism and motoring [10 - 12].

Investigates the percentage differential and power transformer protection methods of the synchronous generator. The modern digital signal can improve the protection of the generator. Ground-type faults are the most common faults in the stator winding of the synchronous machine $[11,13]$.

These faults can be dangerous and can occur severe damages in the generator and their cause is a reduction in the generator speed and consequently in the frequency. The reduction in the frequency of the system below a threshold limit is a signal of abnormality in the power systems [7] and shedding extra load action will be taken by the under-frequency relay. The minimum acceptable limit of the system frequency can be determined by the equipment operation. Generally, in order to operate the system in a continuous mode, the steam turbine must not allow the system frequency below $47.5 \mathrm{~Hz}$ as $50 \mathrm{~Hz}$ is a normal system frequency. Hence, the process would be easy, fast, efficient and more reliable [14].

An adaptive, conventional and intelligence type of load shedding schemes are presented in [2 - 9]. In this paper to overcome this problem, an effective model is simulated which is able to minimize some amount of load by shedding to maintain frequency to its limit (Normal position $50 \mathrm{~Hz}$ ) and system in reliable condition [4]. An under-frequency relay model is presented which checks the response of the power system and can generate a signal in case of any abnormality.

If the system is running in normal operation it cannot work but in case of any abnormality in load-generation, the system response cause change to the original form and the protection system senses the abnormality and under-frequency relay operates. The abnormality of the system may be due to mismatch between load and generation, it means some extra load are connected to the system and frequency of the system cause to reduces which must be minimized to operate system in normal condition and bring frequency in normal condition, so when there is mismatch occur between load and generation an underfrequency relay is modeled which is used to cut off some extra load from the system by doing load shedding to keep power system 
reliability and in normal operating. The under-frequency relay is used to detect reduction in frequency by getting signal from circuit breaker during abnormal conditions of the system and operate automatically [6].

The load must be shaded for possible maximum condition so that systems maintain its normal condition [5]. The frequency relay is settled to remove extra loads to overcome frequency thresholds at different stages [15]. The number and amount of sheds are predecided in the systems [7]. The change in frequency refers directly to deficiency of power $[5,7]$.

\section{System Model}

Single line to ground faults are very dangerous faults and may result in severe damage in stator core and winding [16].
Single line to ground fault is most common fault of insulation failure and cause of burning of weld laminations and iron part. Underfrequency relay is used to determine protection from the fault during abnormal conditions of the load to avoid from such faults [10].

And this damage of winding causes abnormality in a generator because of the increase in the load of the power system which reduces the speed of the generator which directly effects the frequency of the system. There are some tests which performed during abnormal conditions of the load when frequency varies at different rates with the help of a protective relay. A single line diagram under frequency relay for generator protection is shown in figure 1.

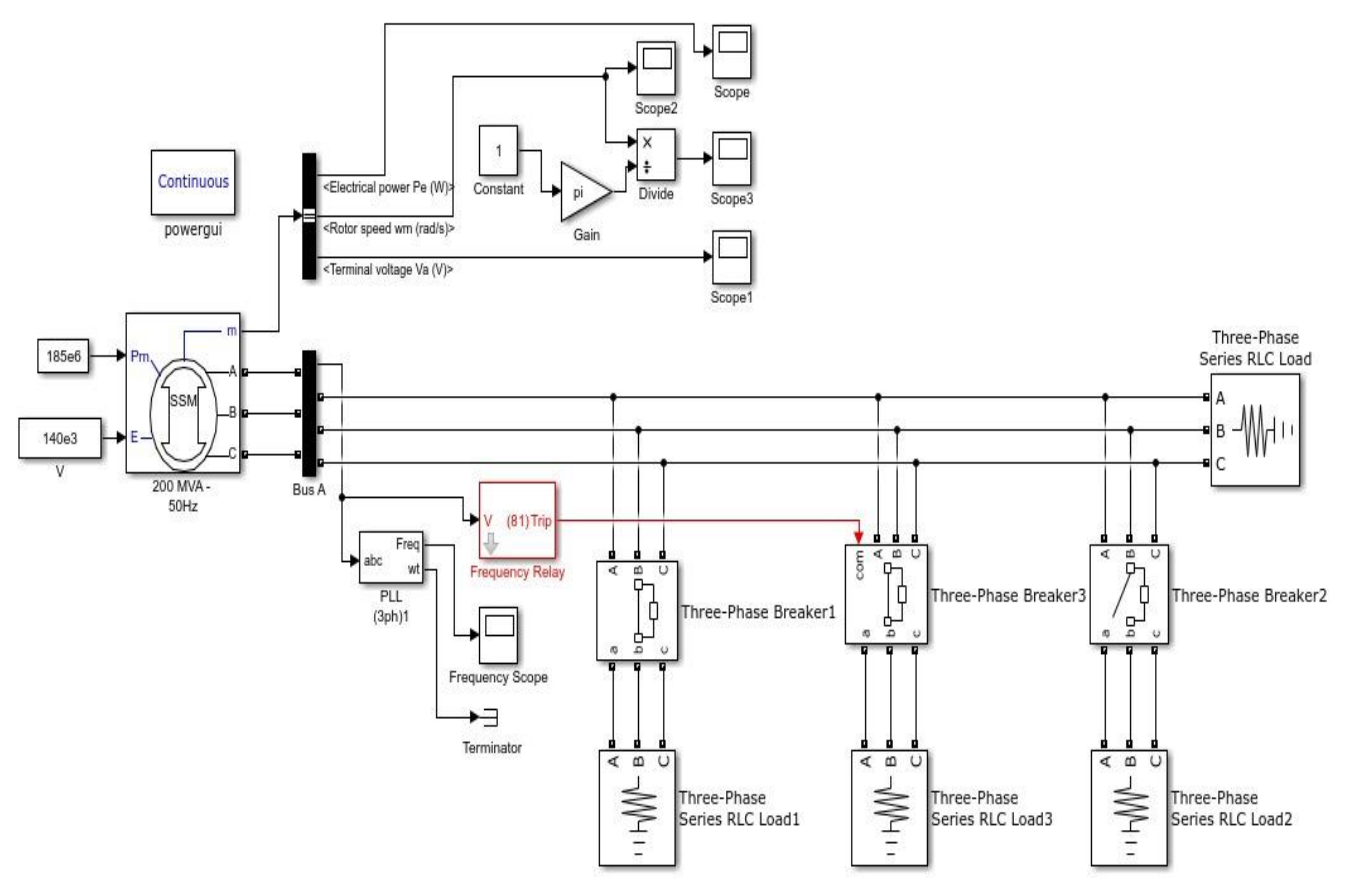

Fig. 1: Modeling of under-frequency relay for generator protection 


\section{Protection System Model}

The frequency of the system can be measured with voltage signal of potential transformer (PT). For the measurement of frequency in graphical way of sine wave is the difference of two consecutive times (T) at zero crossing (T1 and T2) as shown in figure 2.

For the measure of total time of wave form, the factor 2 is multiplied to difference of both consecutive time $\mathrm{T} 1$ and $\mathrm{T} 2$ as shown in equations below:

$$
\begin{aligned}
& T=2 \times\left(T_{2}-T_{1}\right) \\
& \text { Frequency }=\frac{1}{\text { Time Period }(T)}=\frac{1}{2\left(T_{2}-T_{1}\right)}
\end{aligned}
$$

The frequency relay works to compare the two frequencies to maintain system stability. The function of frequency relay is to trip the circuit in case of any abnormalities. This under-frequency relay system is modeled which compares two frequencies, nominal, and variable frequency due to load changes. It compares two frequencies through the generated program shown in figure 3 . If the compared frequency is under limit relay cannot operate and remain in normal operating condition but if in case of any change in the load of the power system there cause a change in frequency and relay operates through a circuit breaker.in case of an abnormal condition, relay generates a signal and sends it to the circuit breaker to cut off extra load to maintain the power system to stabilize and bring frequency under the limit or original frequency $(50 \mathrm{HZ})$.

A phase lock loop (PLL) is used with frequency relay and is a closed-loop control system, which detects the sinusoidal phases of three-phase signal and frequency by internal frequency oscillator as shown in figure 4 . The internal frequency oscillator is controlled by the control system to maintain the phase difference 0 (Zero). It converts a 3-phase i/p signal to Park transformation with the help of

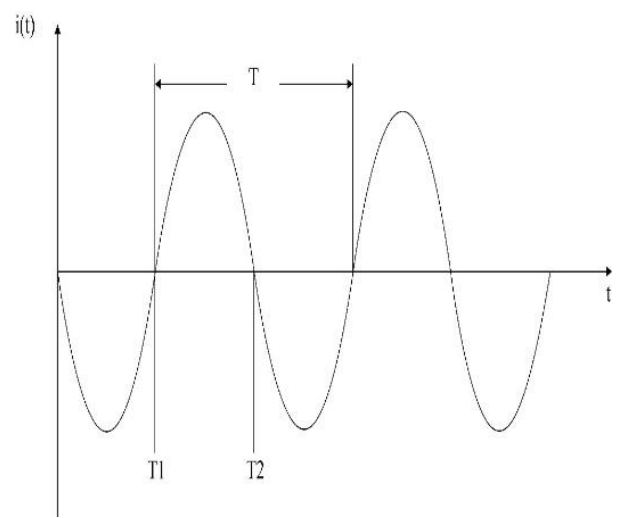

Fig. 2: Measuring of frequency an internal oscillator's angular speed. It is the easiest and simplest electronic circuit that contains a phase detector in feedback and also variable frequency oscillator.

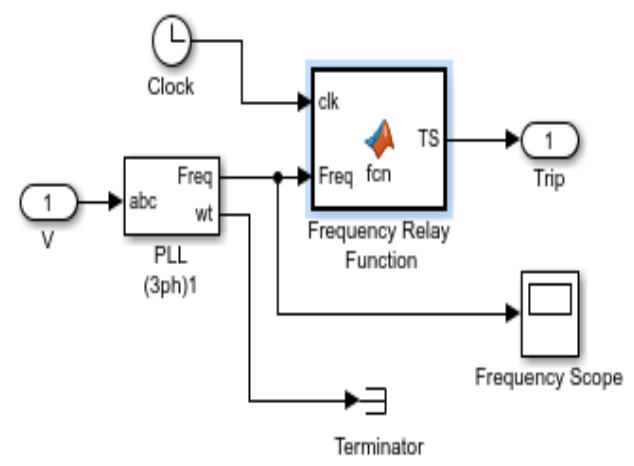

Fig. 3: Frequency Relay

A variable frequency oscillator produces input signal while the phase detector gives the comparison of that generated signal to the phase of an input signal. By keeping the input phase signal and output phase signal equal it maintains the same frequencies of input, and output. Consequently, when an accumulation of synchronizing signals, a PLL tracks the input frequency, or it produces a frequency of multiple inputs. ABC three-phase input signal is converted into dqo (Park transformation) through an internal oscillator by using the angular speed. 


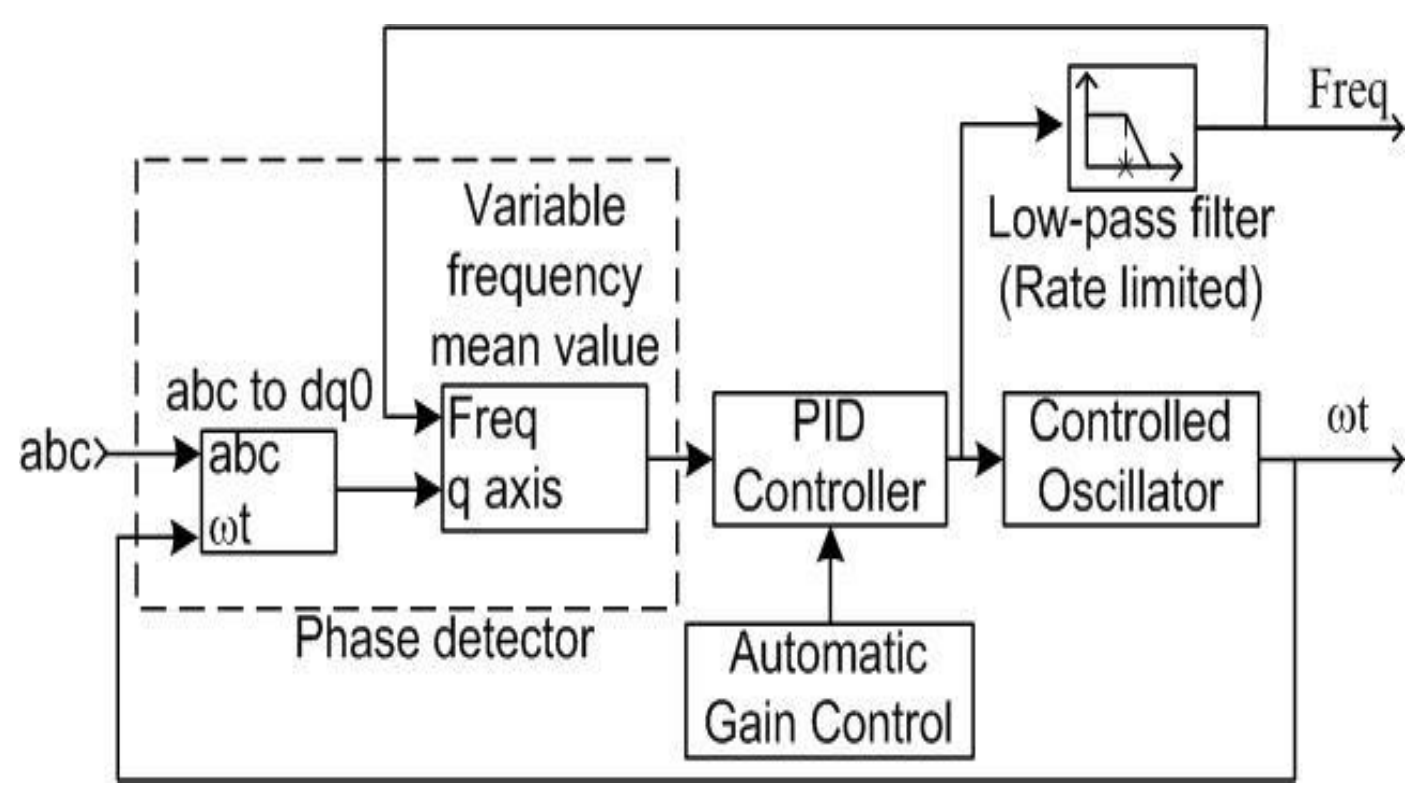

Fig. 4: Internal diagram of PLL

Table I: Relay Setting

\begin{tabular}{|l|l|l|l|l|}
\hline $\begin{array}{l}\text { Under frequency relay } \\
\text { base load shedding }\end{array}$ & $\begin{array}{l}\text { Frequency } \\
\text { threshold }\end{array}$ & $\begin{array}{c}\text { \% load } \\
\text { shed }\end{array}$ & Time delay & $\begin{array}{c}\text { Load shed in } \\
\text { MW }\end{array}$ \\
\hline Step 1 & 48.7 & $15 \%$ & $0.2 \mathrm{sec}$ & $27 \mathrm{MW}$ \\
\hline Step 2 & 48.5 & $18 \%$ & $0.2 \mathrm{sec}$ & $32 \mathrm{~W}$ \\
\hline
\end{tabular}

\section{Simulation Results \& Discussion}

To test the performance of the underfrequency relay, the load variations of $5 \%$ to $20 \%$ have been added and shown in table 1.

The digital under-frequency relay for the generator, protection is based on the frequency variation due to load disturbances in the power system. For this purpose, the under-frequency relay is modeled in MATLAB/Simulink version 2017a and applied on a power system consisting of synchronous generator and load. The performance of this relay is tested at various cases of load variations. The simulation results have shown that an under-frequency relay is capable of detecting and disconnecting the overload within a shorter period of time. The relay has the ability to stabilize the power system within a specified time. 
Case \# 01 the system is operating at the normal condition when the load on the system is minimum of its capacity and suddenly a 27 MW load is added. And the change in frequency is observed as the load has increased, the frequency decreases to $48.7 \mathrm{~Hz}$. Due to this under-frequency relay has detected the abnormality and disconnects the load to bring the frequency to the normal value $(50 \mathrm{~Hz})$ at $20 \mathrm{sec}$ as shown in figure 5 .
Case \# 02 the system is operating at the normal condition when the load on the system is minimum of its capacity and suddenly a 32 MW load is added. The response of the underfrequency relay observed in this case, as the load has increased, the frequency decreases to $48.5 \mathrm{~Hz}$. The under-frequency relay has detected the abnormality and disconnects the load to bring the frequency to the normal value $(50 \mathrm{~Hz})$ at $20 \mathrm{sec}$ shown in figure 6.

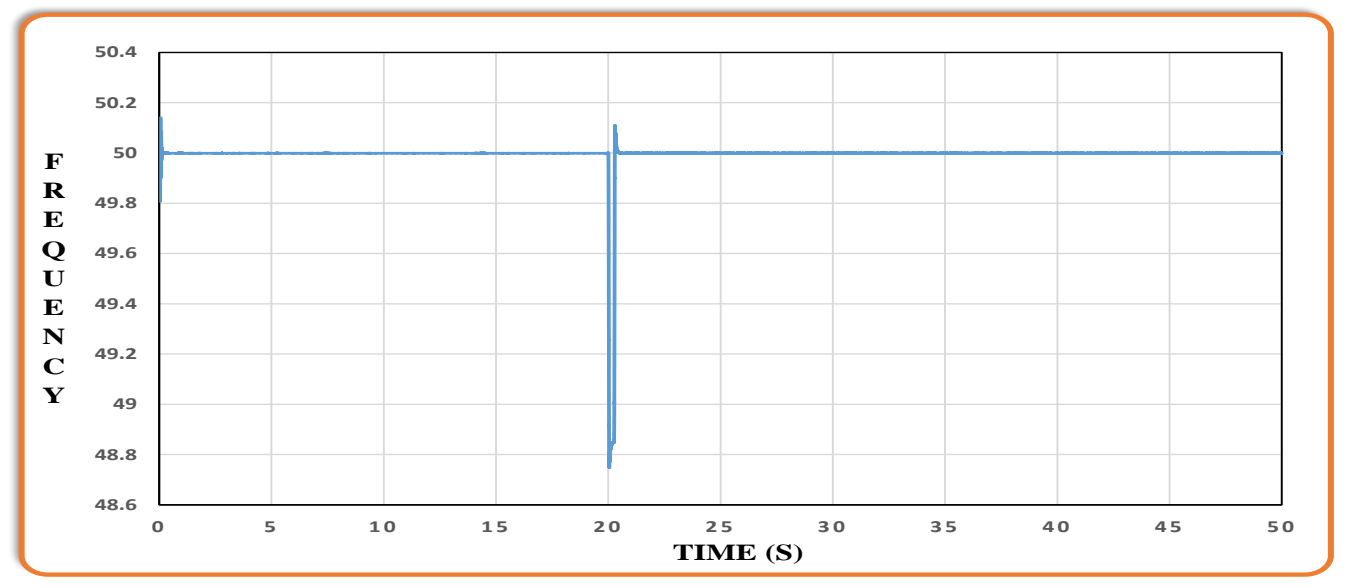

Fig. 5: Under-frequency response when the load varies $15 \%$

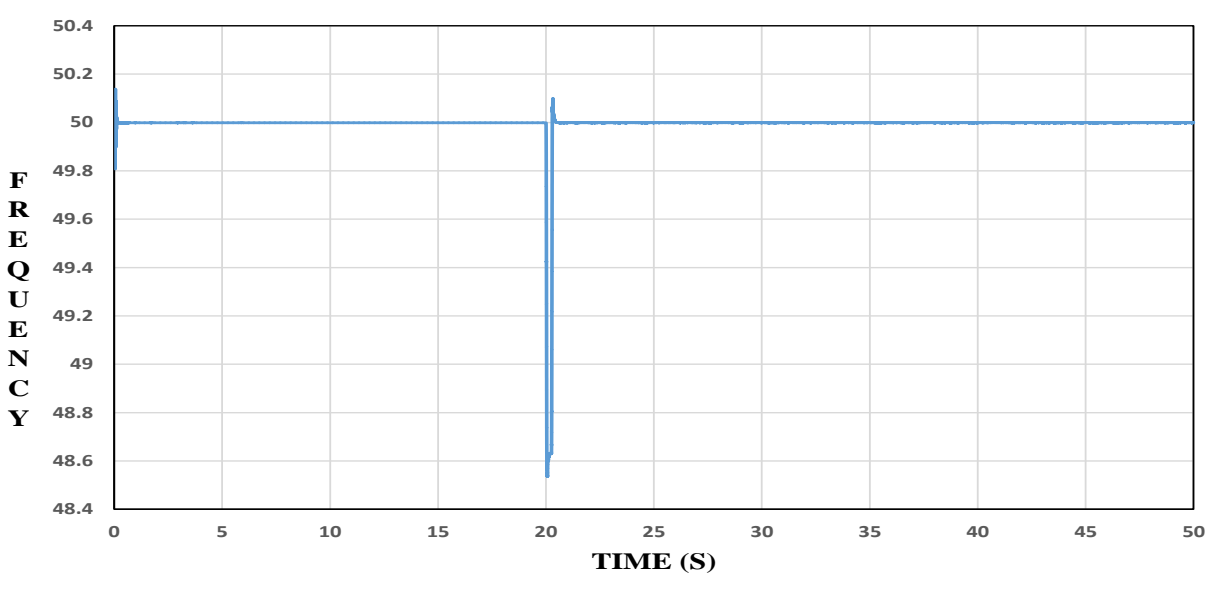

Fig. 6: Under-frequency response when the load varies $18 \%$ 


\section{Conclusion}

However, if there is any unbalanced between load demand and power generation, the system frequency will change and the power system becomes unstable due to these factors, the major blackout may occur in the system. In history several blackout has seen due to instability of frequency or due to unbalancing to meet the demand or removing any of generating unit due to fault occurrence N-1 after distribution of generation and islanding issues, the frequency relays have again get attention of industrialists and researchers. In order to address this issue, this research has presented a digital underfrequency relay scheme to provide efficient and reliable operation of the power system under disturbances. The digital relay has better performance as compared to electromechanical relay due to the parameters such as high speed and accuracy. Digital relays are faster and more accurate than other relays. The main purpose of this work is stabilize the system by controlling the frequency of system by variations of load to the distribution side. In this regard, a synchronous generator with a load model was designed in MATLAB/Simulink software version 2017a. The under-frequency relay for generator protection was also modeled in MATLAB/Simulink software version 2017a. It has been observed from the simulation results that under-frequency relay successfully detects the abnormal response and quickly disconnect the additional loads in order to bring frequency back to its normal state.

In future model can be modify to make system more reliable by adjusting overfrequency relay for better syste. So that system can detect both over and under frequency problem easily.

\section{References}

[1] M. M. Aman et al., "Modeling and simulation of digital negative sequence relay for unbalanced protection of generator", IEEE International Power Engineering and
Optimization Conference Melaka, Malaysia, pp. 72-77, 2012.

[2] C. S. Chen, Y. L. Ke, and C. T. Hsu, "Protective relay setting of the tie line tripping and load shedding for the industrial power system",
Transactions
on Applications, vol. 36, no. 5, pp. 12261234, 2000.

[3] B. Khaki, and S. M. Kouhsari, "Proper setting of under frequency load shedding relays in industrial plants", In 9th IEEE International Conference on Environment and Electrical Engineering, pp. 198-201, 2010.

[4] U. Rudez, and R. Mihalic, "Analysis of under frequency load shedding using a frequency gradient", IEEE transactions on power delivery, vol. 26, no. 2, pp. 565-575, 2011.

[5] H. Bevrani, G. Ledwich, and J. J. Ford, "On the use of $\mathrm{df} / \mathrm{dt}$ in power system emergency control", In IEEE/PES Power Systems Conference and Exposition, pp. $1-6,2009$.

[6] U. K. Jethwa, R. K. Bansal, N. Date, R. Vaishnav, "Comprehensive LoadShedding System", IEEE Transactions on, Industry Applications, vol. 46, no.2, pp.740,749, 2010.

[7] B. Delfino, S. Massucco, A. Morini, P. Scalera, F. Silvestro, "Implementation and comparison of different under frequency load-shedding schemes", Power Engineering Society Summer Meeting, vol. 1, pp. 307- 312, 2001.

[8] C. T. Hsu, "Cogeneration system design for a high-tech science-based industrial park", IEEE Trans. Ind. Appl., vol. 39, no. 5, pp. 1486-1492, 2003.

[9] C. Concordia, L. H. Fink, G. Ponllikkas, "Load shedding on an isolated system", IEEE Transactions on Power Systems, vol. 10, no.3, pp. 1467-1472, 1995.

[10]IEEE Std C37.102TM: IEEE guide for AC generator protection; 2006.

[11]de Morais, Adriano P., et al., "Highsensitivity stator fault protection for synchronous generators: A timedomain approach based on mathematical morphology", \begin{tabular}{llr} 
International & \multicolumn{1}{c}{ Journal of } \\
Electrical & Power \& & Energy
\end{tabular} Systems, 99, pp. 419-425, 2018. 
Ahsan Ali (et al.) Modelling and Simulation of Under -Frequency Relay for Generator Protection (pp.82-89)

[12]M. O. Oliveira, A. S. Bretas, G. D Ferreira, "Adaptive differential protection of three-phase power transformers based on transient signal analysis", Int J Electr Power Energy System, 57, pp. 366-374, 2014.

[13] Y. Wang, J. Zhou, G. Wei, Z. Dong, H. Chen, "Stator winding single-phase grounding faults protective scheme based on discriminant analysis for Powerformers with selectivity", Int J Electr Power Energy System, 77, pp. 145-150, 2016.

[14] J. R. Jones, W. D. Kirkland, "Computer algorithm for selection of frequency relays for load shedding", IEEE Computer Applications in Power, vol. 1, no.1, pp.21,25, 1988.

[15]P. Pinceti, "Emergency load- shedding algorithm for large industrial plants", Control Engineering Practice, 10, pp. 175-181, 2002.

[16] D. Reimert, "Protective relaying for power generation systems", CRC Press Taylor \& Francis Group, 1-545, 2006.

[17] P. Lakra, and M. Kirar, “A comparison of Under Frequency Relay based and Frequency Response model based Load Shedding scheme", In Annual IEEE India

Conference, pp. 1-6, 2015. 